\title{
Effects of odor on emotion, with implications
}

\author{
Mikiko Kadohisa* \\ MRC Cognition and Brain Sciences Unit, Department of Experimental Psychology, University of Oxford, Oxford, UK
}

\section{Edited by:}

Federico Bermudez-Rattoni,

Universidad Nacional Autónoma de

México, Mexico

\section{Reviewed by:}

Federico Bermudez-Rattoni,

Universidad Nacional Autónoma de

México, Mexico

Milagros Gallo, University of Granada, Spain

\section{*Correspondence:}

Mikiko Kadohisa, MRC Cognition and Brain Sciences Unit, Department of

Experimental Psychology, University

of Oxford, South Parks Road, OX1

3UD Oxford, UK

e-mail:miki.kadohisa@psy.ox.ac.uk
The sense of smell is found widely in the animal kingdom. Human and animal studies show that odor perception is modulated by experience and/or physiological state (such as hunger), and that some odors can arouse emotion, and can lead to the recall of emotional memories. Further, odors can influence psychological and physiological states. Individual odorants are mapped via gene-specified receptors to corresponding glomeruli in the olfactory bulb, which directly projects to the piriform cortex and the amygdala without a thalamic relay. The odors to which a glomerulus responds reflect the chemical structure of the odorant. The piriform cortex and the amygdala both project to the orbitofrontal cortex (OFC) which with the amygdala is involved in emotion and associative learning, and to the entorhinal/hippocampal system which is involved in long-term memory including episodic memory. Evidence that some odors can modulate emotion and cognition is described, and the possible implications for the treatment of psychological problems, for example in reducing the effects of stress, are considered.

Keywords: odor, emotion, amygdala, hippocampus, prefrontal cortex

\section{INTRODUCTION}

Inputs received through the sensory systems, individually or together, can produce emotion and influence cognition (LeDoux, 1998; Rolls, 2005; Adolphs, 2010). Emotions can be elicited by stimuli that are instrumental reinforcers (Rolls, 2005). For example, the sight of an impending painful stimulus produces the emotional state of fear, and instrumental actions are performed to avoid the stimulus. Emotional states are generally associated with autonomic responses such as a change in heart rate, and endocrine responses, which are adaptive in that they prepare the body for action. Different reinforcing stimuli arouse different emotional states. Rewarding stimuli are associated with pleasant subjective states, and punishing stimuli with unpleasant subjective states. Human imaging studies have shown that reinforcing visual, auditory, olfactory and taste stimuli activate brain areas such as the orbitofrontal cortex (OFC), and that the activations are linearly correlated with the subjectively reported pleasantness or unpleasantness of the stimuli (Phan et al., 2002; Anderson et al., 2003; Kringelbach et al., 2003; Zald, 2003; Grabenhorst et al., 2007; Anders et al., 2008; Rolls et al., 2008). Odors may be particularly effective stimuli for the recall of memories including emotional memories (Herz, 1996).

The present review addresses two specific questions. First, what is the evidence for a strong link between odors and emotion? Second, what aspects of olfaction and the olfactory system predispose it to produce emotional responses? I begin by reviewing current definitions of emotion, and current views about the neurobiology of odor perception. The unique neuroanatomy and corresponding evolutionary history of the mammalian olfactory system (Lledo et al., 2005) suggest that it could be a very effective, often sub-conscious, driver of emotional responses. Further, the use of pleasant olfactory stimuli, acting as safety signals or reminders of a safe or pleasant event or place, may be useful in the treatment of psychiatric and related conditions, for example reducing anxiety (Lehrner et al., 2000, 2005).

\section{WHAT IS EMOTION?}

Darwin described expressions and gestures that are associated with emotion in humans and other animals (Darwin, 1872). Emotions are also associated with adaptive changes of physiological state including heart rate and endocrine responses (Darwin, 1872; LeDoux, 1998; Rolls, 2005; Adolphs, 2010; LeDoux, 2012). Emotions can usefully be defined as states elicited by stimuli that are rewards or punishers, that is which have value (Rolls, 2005). For example, the "fear" evoked by the smell of a predator is associated with actions to avoid the predator, changes in heart-rate, increased blood flow directed to skeletal muscles, adrenaline release, etc. that maximize the ability to expend energy to escape. Humans might report that this constellation of adaptive autonomic, endocrine, and behavioral responses is associated with an introspective or conscious label of "fear". Although Ekman suggested that there is a set of basic emotions, fear, anger, enjoyment, sadness, disgust, and surprise (Ekman, 1992), a much larger range of emotions can be accounted for if we take into account the rewarding or punishing effects of many different types of reinforcer, such as the taste of food, pleasant touch or pain, and the sight of a beautiful person or scene. Humans and non-human animals alike will perform actions to obtain a stimulus which is a reward, and will perform actions to avoid or escape from a punisher, and these reinforced actions are fundamental to survival and reproductive success (Rolls, 2005).

\section{PERCEPTION OF ODOR}

Odor perception can be influenced by learning and memory (Wilson and Stevenson, 2003a,b, 2006), for example exposure to 
wine or beer significantly improves discrimination (Owen and Machamer, 1979; Peron and Allen, 1988).

The piriform cortex plays a role in odor perception by recoding odor mixtures in such a way that some neurons can respond to an odorant mixture but not to the components (Kadohisa and Wilson, 2006b; Wilson and Sullivan, 2011). In particular, the anterior piriform cortex (aPC) encodes the identity of mixtures of odorants separately from the components, while the posterior piriform cortex ( $\mathrm{pPC}$ ) encodes the similarity between mixtures and their components (Gottfried et al., 2006; Kadohisa and Wilson, 2006b; Wilson and Sullivan, 2011). The implication is that the aPC enables complex mixtures to be represented separately from their components and from each other, while the pPC may enable generalization to similar odors. Another aspect of odor perception is short or long term habituation. aPC neurons adapt to a repeated or prolonged odor rapidly (Wilson, 1998; Wilson and Linster, 2008), which facilitates segmentation of an odor from the background odor, that is, aPC neurons detect a new odor against an adapted background odor (Kadohisa and Wilson, 2006a). This neurophysiological adaptation may be useful in drawing attention to harmful chemicals in adapted background odor environments.

Physiological state influences the perception of odor. For example, the odor of a food will be pleasant during hunger, and its pleasantness will decline as the food is being eaten to satiety (Rolls and Rolls, 1997; Yeshurun and Sobel, 2010). This can be a sensory-specific decrease in the pleasantness of the odor of a food eaten to satiety. In addition, the perception of odors can lead to physiological responses, such as salivation and the release of insulin (Lee and Linden, 1992; Yeomans, 2006; Savigner et al., 2009). Thus physiological state and the effects of odors can interact to influence motivation, for example whether to eat or not. In addition, odors influence autonomic responses, for example pleasant and novel odors can decrease heart rate (Fletcher and Wilson, 2001; Wilson, 2009), while the more sympathetically arousing the odor, the more the skin conductance response increases (Alaoui-Ismaili et al., 1997; Bensafi et al., 2002).

Thus, odor perception is neurophysiologically modulated by experience to facilitate identification of individual odorants including odor mixtures, and to filter out an odor by adaptation, and is also modified by physiological states such as hunger.

\section{OLFACTORY PROCESSING STREAMS IN THE BRAIN}

There are two different olfactory systems. So far, I have considered the main olfactory epithelium (MOE), which projects to the main olfactory bulb (MOB). In addition, there is an accessory olfactory system with its peripheral receptors located in the vomeronasal organ (VNO) which projects to the accessory olfactory bulb (AOB). The VNO contributes to the detection of pheromones while the $\mathrm{MOB}$ detects volatile odors including pheromones. The VNO of mice detects opposite-sex urinary volatiles, in contrast to the MOB which detects volatiles from both sexes (Martel and Baum, 2007; Baum, 2012). The VNOs of humans and old world monkeys are non-functional (Liman and Innan, 2003; Zhang and Webb, 2003; Brennan and Zufall, 2006) although pheromones play important roles in eliciting social and reproductive behavior.
In humans, the MOB may be responsible for pheromone detection (Preti et al., 2003; Wysocki and Preti, 2004).

Considering the main olfactory system, the glomerular layer of the MOB forms odorant receptor maps which reflect individual odorant molecular features (Mori et al., 2006) and the behavioral effects such as escape that they produce (Kobayakawa et al., 2007; Mainen, 2007; Matsumoto et al., 2010; Mori and Sakano, 2011).

Odor information reaches the piriform cortex, amygdala, and entorhinal cortex from the MOB. As shown above, the aPC separates representations of odor mixtures from their components. The piriform cortex projects to the amygdala and prefrontal cortex (PFC) (OFC in primates) (Barbas and De Olmos, 1990; Carmichael et al., 1994; Carmichael and Price, 1995; Pitkanen et al., 2000). The amygdala and PFC are involved in the processes of emotion including emotion-related learning (Zald and Pardo, 1997; Royet et al., 2003; Rolls, 2004) as described below. The MOB and piriform cortex also project to the entorhinal cortex, which in turn projects to the hippocampus where olfactory information can become incorporated into episodic long-term memory (Rolls, 2010; Small et al., 2011; Olsen et al., 2012) as described below.

Amygdala: The MOB projects directly to the anterior cortical nucleus and medial nucleus of amygdala, and the periamygdaloid cortex in rodents and macaques (Turner et al., 1978; Turner and Mishkin, 1978; Carmichael et al., 1994; McDonald, 1998), while the AOB projects to the medial nucleus of the amygdala in rodents (Keverne, 1999; Pitkanen, 2000; Kang et al., 2009). The medial nucleus of the amygdala is thought to be a place for inputs from the $\mathrm{AOB}$ and $\mathrm{MOB}$ of rodents to interact with each other (Brennan and Zufall, 2006; Baum, 2012). In addition, the piriform cortex projects directly to the basolateral nucleus of amygdala in both rodents and macaques (Carmichael et al., 1994; McDonald, 1998). Further, the amygdala projects to the hypothalamus (Pitkanen, 2000; Barbas et al., 2003; Gabbott et al., 2012), which may provide a route for olfactory stimuli to influence the autonomic and endocrine systems.

The amygdala plays a key role in some affective responses to stimuli. Amygdala-lesioned animals show a lack of reactions such as freezing, and autonomic responses, to a fear conditioned stimulus (CS; Weiskrantz, 1956; Helmstetter, 1992; Phillips and LeDoux, 1992; Sananes and Davis, 1992), and show abnormal food preferences including reduced neophobia (Rolls and Rolls, 1973; Murray et al., 1996). In addition, the amygdala plays a role in associative learning, for example, some amygdala neurons encode odor cues associated with a positive or negative taste (Schoenbaum et al., 1999).

Hippocampus: The hippocampus receives olfactory information from the amygdala (Petrovich et al., 2001) and from the entorhinal cortex which receives inputs from the MOB and piriform cortex (Price, 1973; Witter and Amaral, 1991; Carmichael et al., 1994).

The hippocampus plays a fundamental role in episodic memory (Lemogne et al., 2006; Rolls, 2010; Small et al., 2011; Olsen et al., 2012). Hippocampal damage impairs odor-place associative learning, and temporal order memory for odor information (Kesner et al., 2002; Rolls and Kesner, 2006). Some neurons in the hippocampus represent the place of odor-related reward (Rolls, 2010; Tort et al., 2011). In addition, stimulation of the 
hippocampus affects autonomic responses, that is, decreases heart rate and blood pressure (Ruit and Neafsey, 1988).

Prefrontal cortex: The primate OFC receives olfactory information from the piriform cortex (Carmichael and Price, 1994), the amygdala (Amaral and Price, 1984; Ghashghaei and Barbas, 2002; Barbas et al., 2003), parahippocampal cortices (Carmichael and Price, 1995), and from the hypothalamus (Tanabe et al., 1975; Barbas et al., 2003).

The OFC associates olfactory with taste, oral texture, and visual inputs, to produce multimodal representations of reward value, such as the reward value of food (Rolls, 2012). The OFC representations are of the economic value of goods, e.g., of a food (Padoa-Schioppa, 2011). The reward evaluation performed by the OFC is important in both emotion and in autonomic responses such as heart rate and skin conductance responses (Damasio, 1995; Bechara et al., 1996).

In addition, the amygdala, OFC, and hippocampus are also involved in the regulation of stress which causes not only psychological and psychiatric but also physiological problems (see Mcewen, 2007; Arnsten, 2009; Rodrigues et al., 2009; Ulrich-Lai and Herman, 2009). As described below, the olfactory pathways may enable some odorants to influence stress in a therapeutic way.

\section{ODOR-EVOKED EMOTION AND ODOR-ASSOCIATED EMOTIONAL MEMORY}

There is evidence that odors elicit emotion and are linked to emotional memory. Responses to odors can include emotions, which can usefully be defined as states elicited by stimuli that are rewards and punishers (Rolls, 2005). For examples, a predator's odor can cause a prey to escape from it, while newborn babies move towards the breast odor of their own mother (Varendi and Porter, 2001). Different odors can elicit individual affective responses which may be pleasant or unpleasant (Chrea et al., 2009; Seubert et al., 2009, 2010). Emotionally arousing odors may influence cognition and emotion. Some odors facilitate the recognition of disgust face expressions (Seubert et al., 2010) and impair working memory (Schneider et al., 2006; Habel et al., 2007) while others reduce anger (Rétiveau et al., 2004) or improve mood (Schiffman et al., 1995). In addition, some affective odors modulate psychological and physiological state. Komori and colleagues (Komori et al., 1995) reported effects of citrus fragrance on the improvement of psychological states and immune function of patients with depression. Green odor emanating from oak leaves is necessary for polyphemus moths to mate (Riddiford, 1967), and elicits pleasantness from humans (Sano et al., 2002). In addition, green odor attenuates the stress-induced elevations of plasma adrenocorticotropic hormone (ACTH), body temperature (Nakashima et al., 2004), and skin-barrier disruption in rats (Fukada et al., 2007). Similarly, rose essential oil inhibits stress-induced skinbarrier disruption and elevation of salivary cortisol in humans (Fukada et al., 2012), and orange and lavender reduce the anxiety of patients in a dental office (Lehrner et al., 2000, 2005).

Odors can become associated by learning with reinforcers such as taste in the OFC and amygdala, and this provides a way for previously neutral odors to produce emotional responses (Herz et al., 2004; Rolls, 2005). Patients frightened by dental treatment respond negatively to the smell of eugenol which is used for treatment (Robin et al., 1998). Odor-evoked autobiographical memory is powerful in reminding humans about past emotional experiences (Chu and Downes, 2002; Larsson and Willander, 2009; Zucco et al., 2012). This odor associative memory and learning begins early in life (Schaal et al., 2000; Larsson and Willander, 2009). For examples, the foods eaten by a pregnant mother can influence the odors liked by her offspring (Schaal et al., 2000), and neonatal rats at ages of less than 3 days learn the odor associated with aversive or rewarded outcomes (Rudy and Cheatle, 1977; Johanson and Hall, 1979). Further, this associative learning regulates behavior, that is, when animals have learned associations between an odor CS and a negative outcome such as foot shock unconditioned stimulus (US), they try to avoid the CS associated with the negative US, or show fear expressions such as freezing (Sullivan et al., 2000; Sacco and Sacchetti, 2010).

The amygdala, OFC and hippocampus are involved in the process of odor-elicited emotion and odor-associated emotional memory. Human imaging studies have demonstrated that the amygdala and OFC are activated by unpleasant or pleasant odors, consistent with their functions in emotion (Zald and Pardo, 1997; Royet et al., 2003; Small et al., 2003). Consistently, activations of the human OFC elicited by odors correlate with the subjective pleasantness or unpleasantness of the odors (Rolls, 2000; Anderson et al., 2003; Grabenhorst et al., 2007). Amygdala lesions impair learned odor preferences in infant rats (Sullivan and Wilson, 1993) while hippocampus and subiculum lesions in rats produce a deficit in social learning of an odor association (Alvarez et al., 2002). In humans, the amygdala and PFC of patients with posttraumatic stress disorder (PTSD) are activated by exposure to the odor related to the traumatic memory (Vermetten et al., 2007) while the hippocampus and PFC are activated by odor cues during autobiographical memory retrieval process (Larsson and Willander, 2009).

The odor mapping performed in the aPC may set up representations of odors that are separate, even when considering odorant mixtures and their components (Kadohisa and Wilson, 2006b; Wilson and Sullivan, 2011). This pattern separation of the representations of even odorant mixtures using non-linear remapping is useful for the pattern association learning of odors to taste and visual representations performed in the OFC and amygdala to represent the reward/emotional value of the odor object (Rolls, 2008), and for the autoassociative formation of episodic memory performed in the hippocampus (Rolls, 2010).

\section{CONCLUSIONS}

Human and complementary studies in non-human animals provide evidence that odors evoke emotion and autonomic state via pathways to the amygdala and OFC, and become incorporated into episodic memory via the hippocampus.

In addition, it is suggested that some odorants which elicit emotion may have potential to treat patients with psychological problem such as depression.

\section{ACKNOWLEDGMENTS}

I greatly appreciate comments on an earlier draft of this paper provided by Professor D.A. Wilson (NKI and NYU/CNS). 


\section{REFERENCES}

Adolphs, R. (2010). Social cognition: feeling voices to recognize emotions. Curr. Biol. 20, R1071-R1072. doi: 10.1016/j.cub.2010.11.019

Alaoui-Ismaili, O., Vernet-Maury, E., Dittmar, A., Delhomme, G., and Chanel, J. (1997). Odor hedonics: connection with emotional response estimated by autonomic parameters. Chem. Senses 22, 237 248. doi: 10.1093/chemse/22.3. 237

Alvarez, P., Wendelken, L., and Eichenbaum, H. (2002). Hippocampal formation lesions impair performance in an odor-odor association task independently of spatial context. Neurobiol. Learn. Mem. 78, 470-476. doi: 10.1006/nlme.2002. 4068

Amaral, D. G., and Price, J. L. (1984). Amygdalo-cortical projections in the monkey (Macaca fascicularis). J. Comp. Neurol. 230, 465-496. doi: 10.1002/cne.902300402

Anders, S., Eippert, F., Weiskopf, N., and Veit, R. (2008). The human amygdala is sensitive to the valence of pictures and sounds irrespective of arousal: an fMRI study. Soc. Cogn. Affect. Neurosci. 3, 233-243. doi: 10. 1093/scan/nsn017

Anderson, A. K., Christoff, K., Stappen, I., Panitz, D., Ghahremani, D. G., Glover, G., et al. (2003). Dissociated neural representations of intensity and valence in human olfaction. Nat. Neurosci. 6, 196-202. doi: 10. 1038/nn 1001

Arnsten, A. F. (2009). Stress signalling pathways that impair prefrontal cortex structure and function. Nat. Rev. Neurosci. 10, 410-422. doi: 10. 1038/nrn2648

Barbas, H., and De Olmos, J. (1990). Projections from the amygdala to basoventral and mediodorsal prefrontal regions in the rhesus monkey. J. Comp. Neurol. 300, 549-571. doi: $10.1002 / \mathrm{cne} .903000409$

Barbas, H., Saha, S., Rempel-Clower, N., and Ghashghaei, T. (2003). Serial pathways from primate prefrontal cortex to autonomic areas may influence emotional expression. BMC Neurosci. 4:25. doi: 10. 1186/1471-2202-4-25

Baum, M. J. (2012). Contribution of pheromones processed by the main olfactory system to mate recognition in female mammals. Front. Neuroanat. 6:20. doi: 10.3389/fnana. 2012.00020

Bechara, A., Tranel, D., Damasio, H., and Damasio, A. R. (1996). Failure to respond autonomically to anticipated future outcomes following damage to prefrontal cortex.
Cereb. Cortex 6, 215-225. doi: 10. 1093/cercor/6.2.215

Bensafi, M., Rouby, C., Farget, V., Bertrand, B., Vigouroux, M., and Holley, A. (2002). Autonomic nervous system responses to odours: the role of pleasantness and arousal. Chem. Senses 27, 703-709. doi: 10.1093/chemse/27.8. 703

Brennan, P. A., and Zufall, F. (2006). Pheromonal communication in vertebrates. Nature 444, 308-315. doi: 10.1038/nature05404

Carmichael, S. T., Clugnet, M. C., and Price, J. L. (1994). Central olfactory connections in the macaque monkey. J. Comp. Neurol. 346, 403-434. doi: 10.1002/cne.903460306

Carmichael, S. T., and Price, J. L. (1994). Architectonic subdivision of the orbital and medial prefrontal cortex in the macaque monkey. $J$. Comp. Neurol. 346, 366-402. doi: 10. 1002/cne.903460305

Carmichael, S. T., and Price, J. L. (1995). Limbic connections of the orbital and medial prefrontal cortex in macaque monkeys. J. Comp. Neurol. 363, 615-641. doi: 10.1002/cne. 903630408

Chrea, C., Grandjean, D., Delplanque, S., Cayeux, I., Le Calve, B., Aymard, L., et al. (2009). Mapping the semantic space for the subjective experience of emotional responses to odors. Chem. Senses 34, 49-62. doi: 10.1093/chemse/bjn052

Chu, S., and Downes, J. J. (2002). Proust nose best: odors are better cues of autobiographical memory. Mem. Cognit. 30, 511-518. doi: 10. 3758/bf03194952

Damasio, A. R. (1995). On some functions of the human prefrontal cortex. Ann. N Y Acad. Sci. 769, 241251. doi: 10.1111/j.1749-6632.1995. tb38142.x

Darwin, C. (1872). The Expression of the Emotions in Man and Animals. Leipzig: Amazon.

Ekman, P. (1992). Facial expressions of emotion: an old controversy and new findings. Philos. Trans. R. Soc. Lond. B Biol. Sci. 335, 63-69. doi: 10. 1098/rstb.1992.0008

Fletcher, M., and Wilson, D. A. (2001). Ontogeny of odor discrimination: a method to assess novel odor discrimination in neonatal rats. Physiol. Behav. 74, 589-593. doi: 10 1016/s0031-9384(01)00602-3

Fukada, M., Kaidoh, T., Ito, A., Yano, T., Hayashibara, C., and Watanabe, T. (2007). "Green odor" inhalation reduces the skin-barrier disruption induced by chronic restraint stress in rats: physiological and histological examinations.
Chem. Senses 32, 633-639. doi: 10. 1093/chemse/bjm031

Fukada, M., Kano, E., Miyoshi, M., Komaki, R., and Watanabe, T. (2012). Effect of "rose essential oil" inhalation on stress-induced skin-barrier disruption in rats and humans. Chem. Senses 37, 347-356. doi: 10.1093/chemse/bjr108

Gabbott, P., Warner, T. A., Brown, J., Salway, P., Gabbott, T., and Busby, S. (2012). Amygdala afferents monosynaptically innervate corticospinal neurons in rat medial prefrontal cortex. J. Comp. Neurol. 520, 2440 2458. doi: 10.1002/cne.23047

Ghashghaei, H. T., and Barbas, H. (2002). Pathways for emotion: interactions of prefrontal and anterior temporal pathways in the amygdala of the rhesus monkey. Neuroscience 115, 1261-1279. doi: 10.1016/s03064522(02)00446-3

Gottfried, J. A., Winston, J. S., and Dolan, R. J. (2006). Dissociable codes of odor quality and odorant structure in human piriform cortex. Neuron 49, 467-479. doi: 10.1016/j. neuron.2006.01.007

Grabenhorst, F., Rolls, E. T., Margot, C., da Silva, M. A., and Velazco, M. I. (2007). How pleasant and unpleasant stimuli combine in different brain regions: odor mixtures. J. Neurosci. 27, 13532-13540. doi: 10. 1523/jneurosci.3337-07.2007

Habel, U., Koch, K., Pauly, K., Kellermann, T., Reske, M., Backes, V., et al. (2007). The influence of olfactoryinduced negative emotion on verbal working memory: individual differences in neurobehavioral findings. Brain Res. 1152, 158-170. doi: 10. 1016/j.brainres.2007.03.048

Helmstetter, F. J. (1992). Contribution of the amygdala to learning and performance of conditional fear. Physiol. Behav. 51, 1271-1276. doi: 10. 1016/0031-9384(92)90320-2

Herz, R. S. (1996). A comparison of olfactory, tactile and visual as associated memory cues. Chem. Senses 21, 614-615.

Herz, R. S., Schankler, C., and Beland, S. (2004). Olfaction, emotion and associative learning: effects on motivated behavior. Motiv. Emotion 28, 363-383. doi: 10.1007/s11031-0042389-x

Johanson, I. B., and Hall, W. G. (1979). Appetitive learning in 1-day-old rat pups. Science 205, 419-421. doi: 10. $1126 /$ science. 451612

Kadohisa, M., and Wilson, D. A. (2006a). Olfactory cortical adaptation facilitates detection of odors against background. J. Neurophysiol. 95, 1888-1896. doi: 10.1152/jn. 00812.2005
Kadohisa, M., and Wilson, D. A. (2006b). Separate encoding of identity and similarity of complex familiar odors in piriform cortex. Proc. Natl. Acad. Sci. U S A 103, 15206-15211. doi: 10.1073/pnas. 0604313103

Kang, N., Baum, M. J., and Cherry, J. A. (2009). A direct main olfactory bulb projection to the 'vomeronasal' amygdala in female mice selectively responds to volatile pheromones from males. Eur. J. Neurosci. 29, 624-634. doi: 10.1111/j.1460-9568. 2009.06638.x

Kesner, R. P., Gilbert, P. E., and Barua, L. A. (2002). The role of the hippocampus in memory for the temporal order of a sequence of odors. Behav. Neurosci. 116, 286290. doi: 10.1037/0735-7044.116.2. 286

Keverne, E. B. (1999). The vomeronasal organ. Science 286, 716720. doi: 10.1126/science.286. 5440.716

Kobayakawa, K., Kobayakawa, R., Matsumoto, H., Oka, Y., Imai, T., Ikawa, M., et al. (2007). Innate versus learned odour processing in the mouse olfactory bulb. Nature 450, 503-508. doi: 10.1038/ nature 06281

Komori, T., Fujiwara, R., Tanida, M., Nomura, J., and Yokoyama, M. M. (1995). Effects of citrus fragrance on immune function and depressive states. Neuroimmunomodulation 2, 174-180. doi: 10.1159/000096889

Kringelbach, M. L., O'doherty, J., Rolls, E. T., and Andrews, C. (2003). Activation of the human orbitofrontal cortex to a liquid food stimulus is correlated with its subjective pleasantness. Cereb. Cortex 13, 1064-1071. doi: 10.1093/cercor/13. 10.1064

Larsson, M., and Willander, J. (2009). Autobiographical odor memory. Ann. N Y Acad. Sci. 1170, 318-323. doi: $\quad 10.1111 /$ j.1749-6632.2009. 03934.x

LeDoux, J. (1998). The Emotional Brain. New York: Phoenix.

LeDoux, J. (2012). Rethinking the emotional brain. Neuron 73, 653-676. doi: 10.1016/j.neuron.2012.02.018

Lee, V. M., and Linden, R. W. (1992). An olfactory-submandibular salivary reflex in humans. Exp. Physiol. 77, 221-224.

Lehrner, J., Eckersberger, C., Walla, P., Potsch, G., and Deecke, L. (2000). Ambient odor of orange in a dental office reduces anxiety and improves mood in female patients. Physiol. Behav. 71, 8386. doi: 10.1016/s0031-9384(00) 00308-5 
Lehrner, J., Marwinski, G., Lehr, S., Johren, P., and Deecke, L. (2005). Ambient odors of orange and lavender reduce anxiety and improve mood in a dental office. Physiol. Behav. 86, 92-95. doi: 10.1016/j. physbeh.2005.06.031

Lemogne, C., Piolino, P., Friszer, S., Claret, A., Girault, N., Jouvent, R., et al. (2006). Episodic autobiographical memory in depression: specificity, autonoetic consciousness, and self-perspective. Conscious Cogn. 15, 258-268. doi: 10.1016/j.concog.2005.07.005

Liman, E. R., and Innan, H. (2003). Relaxed selective pressure on an essential component of pheromone transduction in primate evolution. Proc. Natl. Acad. Sci. U S A 100, 3328-3332. doi: 10.1073/pnas. 0636123100

Lledo, P. M., Gheusi, G., and Vincent, J. D. (2005). Information processing in the mammalian olfactory system. Physiol. Rev. 85, 281-317. doi: 10. 1152/physrev.00008.2004

Mainen, Z. F. (2007). The main olfactory bulb and innate behavior: different perspectives on an olfactory scene. Nat. Neurosci. 10, 1511-1512. doi: 10.1038/nn1207-1511

Martel, K. L., and Baum, M. J. (2007). Sexually dimorphic activation of the accessory, but not the main, olfactory bulb in mice by urinary volatiles. Eur. J. Neurosci. 26, $463-$ 475. doi: 10.1111/j.1460-9568.2007. 05651.x

Matsumoto, H., Kobayakawa, K., Kobayakawa, R., Tashiro, T., Mori, K., Sakano, H., et al. (2010). Spatial arrangement of glomerular molecular-feature clusters in the odorant-receptor class domains of the mouse olfactory bulb. J. Neurophysiol. 103, 3490-3500. doi: 10.1152/jn.00035.2010

McDonald, A. J. (1998). Cortical pathways to the mammalian amygdala. Prog. Neurobiol. 55, 257332. doi: $10.1016 / \mathrm{s} 0301-0082(98)$ 00003-3

Mcewen, B. S. (2007). Physiology and neurobiology of stress and adaptation: central role of the brain. Physiol. Rev. 87, 873-904. doi: 10. 1152/physrev.00041.2006

Mori, K., and Sakano, H. (2011). How is the olfactory map formed and interpreted in the mammalian brain? Annu. Rev. Neurosci. 34, 467499. doi: 10.1146/annurev-neuro112210-112917

Mori, K., Takahashi, Y. K., Igarashi, K. M., and Yamaguchi, M. (2006). Maps of odorant molecular features in the Mammalian olfactory bulb.
Physiol. Rev. 86, 409-433. doi: 10. 1152/physrev.00021.2005

Murray, E. A., Gaffan, E. A., and Flint, R. W. Jr. (1996). Anterior rhinal cortex and amygdala: dissociation of their contributions to memory and food preference in rhesus monkeys. Behav. Neurosci. 110, 30-42. doi: 10. 1037/0735-7044.110.1.30

Nakashima, T., Akamatsu, M., Hatanaka, A., and Kiyohara, T. (2004). Attenuation of stressinduced elevations in plasma ACTH level and body temperature in rats by green odor. Physiol. Behav. 80, 481-488. doi: 10.1016/j.physbeh. 2003.10.008

Olsen, R. K., Moses, S. N., Riggs, L., and Ryan, J. D. (2012). The hippocampus supports multiple cognitive processes through relational binding and comparison. Front. Hum. Neurosci. 6:146. doi: 10.3389/fnhum. 2012.00146

Owen, D. H., and Machamer, P. K. (1979). Bias-free improvement in wine discrimination. Perception 8, 199-209. doi: 10.1068/p080199

Padoa-Schioppa, C. (2011). Neurobiology of economic choice: a goodbased model. Annu. Rev. Neurosci. 34, 333-359. doi: 10.1146/annurevneuro-061010-113648

Peron, R. M., and Allen, G. L. (1988). Attempts to train novices for beer flavor discrimination: a matter of taste. J. Gen. Psychol. 115, 403418. doi: 10.1080/00221309.1988. 9710577

Petrovich, G. D., Canteras, N. S., and Swanson, L. W. (2001). Combinatorial amygdalar inputs to hippocampal domains and hypothalamic behavior systems. Brain Res. Brain Res. Rev. 38, 247-289. doi: 10. 1016/s0165-0173(01)00080-7

Phan, K. L., Wager, T., Taylor, S. F., and Liberzon, I. (2002). Functional neuroanatomy of emotion: a metaanalysis of emotion activation studies in PET and fMRI. Neuroimage 16, 331-348. doi: 10.1006/nimg. 2002.1087

Phillips, R. G., and LeDoux, J. E. (1992). Differential contribution of amygdala and hippocampus to cued and contextual fear conditioning. Behav. Neurosci. 106, 274-285. doi: 10.1037/0735-7044.106.2.274

Pitkanen, A. (2000). The Amygdala. Oxford: Oxford University Press.

Pitkanen, A., Pikkarainen, M., Nurminen, N., and Ylinen, A. (2000). Reciprocal connections between the amygdala and the hippocampal formation, perirhinal cortex, and postrhinal cortex in rat. A review. Ann. N Y Acad. Sci. 911,
369-391. doi: 10.1111/j.1749-6632. 2000.tb06738.x

Preti, G., Wysocki, C. J., Barnhart, K. T., Sondheimer, S. J., and Leyden, J. J. (2003). Male axillary extracts contain pheromones that affect pulsatile secretion of luteinizing hormone and mood in women recipients. Biol. Reprod. 68, 2107-2113. doi: 10.1095/biolreprod.102.008268

Price, J. L. (1973). An autoradiographic study of complementary laminar patterns of termination of afferent fibers to the olfactory cortex. J. Comp. Neurol. 150, 87-108. doi: 10. 1002/cne.901500105

Rétiveau, A. N., Chambers IV, E., and Milliken, G. A. (2004). Common and specific effects of fine fragrances on the mood of women. J. Sens. Stud. 19, 373-394. doi: 10.1111/j. 1745-459x.2004.102803.x

Riddiford, L. M. (1967). Trans-2hexenal: mating stimulant for polyphemus moths. Science 158, 139-141. doi: 10.1126/science.158. 3797.139

Robin, O., Alaoui-Ismaili, O., Dittmar, A., and Vernet-Maury, E. (1998). Emotional responses evoked by dental odors: an evaluation from autonomic parameters. $J$. Dent. Res. 77, 1638-1646. doi: 10. 1177/00220345980770081201

Rodrigues, S. M., Ledoux, J. E., and Sapolsky, R. M. (2009). The influence of stress hormones on fear circuitry. Annu. Rev. Neurosci. 32, 289-313. doi: 10.1146/annurev. neuro.051508.135620

Rolls, E. T. (2000). The orbitofrontal cortex and reward. Cereb. Cortex 10, 284-294. doi: 10.1093/cercor/10.3. 284

Rolls, E. T. (2004). Convergence of sensory systems in the orbitofrontal cortex in primates and brain design for emotion. Anat. Rec. A Discov. Mol. Cell. Evol. Biol. 281, 1212-1225. doi: 10.1002/ar.a.20126

Rolls, E. T. (2005). Emotion Explained. Oxford: Oxford University Press.

Rolls, E. T. (2008). Memory, Attention, and Decision-Making. Oxford: Oxford University Press.

Rolls, E. T. (2010). A computational theory of episodic memory formation in the hippocampus. Behav. Brain Res. 215, 180-196. doi: 10. 1016/j.bbr.2010.03.027

Rolls, E. T. (2012). Taste, olfactory and food texture reward processing in the brain and the control of appetite. Proc. Nutr. Soc. 1-14. doi: 10.1017/s0029665112000821

Rolls, E. T., Grabenhorst, F., and Parris, B. A. (2008). Warm pleasant feelings in the brain. Neuroim- age 41, 1504-1513. doi: 10.1016/j. neuroimage.2008.03.005

Rolls, E. T., and Kesner, R. P. (2006). A computational theory of hippocampal function, and empirical tests of the theory. Prog. Neurobiol. 79, 148. doi: 10.1016/j.pneurobio.2006. 04.005

Rolls, E. T., and Rolls, B. J. (1973). Altered food preferences after lesions in the basolateral region of the amygdala in the rat. J. Comp. Physiol. Psychol. 83, 248-259. doi: 10.1037/h0034414

Rolls, E. T., and Rolls, J. H. (1997). Olfactory sensory-specific satiety in humans. Physiol. Behav. 61, 461-473. doi: 10.1016/s00319384(96)00464-7

Royet, J. P., Plailly, J., DelonMartin, C., Kareken, D. A., and Segebarth, C. (2003). fMRI of emotional responses to odors: influence of hedonic valence and judgment, handedness, and gender. Neuroimage 20, 713-728. doi: 10. 1016/S1053-8119(03)00388-4

Rudy, J. W., and Cheatle, M. D. (1977). Odor-aversion learning in neonatal rats. Science 198, 845-846. doi: 10. $1126 /$ science. 918668

Ruit, K. G., and Neafsey, E. J. (1988). Cardiovascular and respiratory responses to electrical and chemical stimulation of the hippocampus in anesthetized and awake rats. Brain Res. 457, 310-321. doi: 10. 1016/0006-8993(88)90701-9

Sacco, T., and Sacchetti, B. (2010). Role of secondary sensory cortices in emotional memory storage and retrieval in rats. Science 329, 649656. doi: 10.1126/science. 1183165

Sananes, C. B., and Davis, M. (1992). $\mathrm{N}$-methyl-D-aspartate lesions of the lateral and basolateral nuclei of the amygdala block fear-potentiated startle and shock sensitization of startle. Behav. Neurosci. 106, 72-80. doi: 10.1037/0735-7044.106.1.72

Sano, K., Tsuda, Y., Sugano, H., Aou, S., and Hatanaka, A. (2002). Concentration effects of green odor on event-related potential (P300) and pleasantness. Chem. Senses 27, 225230. doi: 10.1093/chemse/27.3.225

Savigner, A., Duchamp-Viret, P., Grosmaitre, X., Chaput, M., Garcia, S. Ma, M., et al. (2009). Modulation of spontaneous and odorantevoked activity of rat olfactory sensory neurons by two anorectic peptides, insulin and leptin. J. Neurophysiol. 101, 2898-2906. doi: 10. 1152/jn.91169.2008

Schaal, B., Marlier, L., and Soussignan, R. (2000). Human foetuses learn odours from their pregnant 
mother's diet. Chem. Senses 25, 729-737. doi: 10.1093/chemse/25.6. 729

Schiffman, S. S., Suggs, M. S., and Sattely-Miller, E. A. (1995). Effect of pleasant odors on mood of males at midlife: comparison of AfricanAmerican and European-American men. Brain Res. Bull. 36, 31-37. doi: 10.1016/0361-9230(94)00134$\mathrm{m}$

Schneider, F., Gur, R. C., Koch, K., Backes, V., Amunts, K., Shah, N. J., et al. (2006). Impairment in the specificity of emotion processing in schizophrenia. Am. J. Psychiatry 163, 442-447. doi: 10.1176/appi.ajp.163. 3.442

Schoenbaum, G., Chiba, A. A., and Gallagher, M. (1999). Neural encoding in orbitofrontal cortex and basolateral amygdala during olfactory discrimination learning. J. Neurosci. 19, 1876-1884.

Seubert, J., Kellermann, T., Loughead, J., Boers, F., Brensinger, C., Schneider, F., et al. (2010). Processing of disgusted faces is facilitated by odor primes: a functional MRI study. Neuroimage 53, 746-56. doi: 10. 1016/j.neuroimage.2010.07.012

Seubert, J., Rea, A. F., Loughead, J., and Habel, U. (2009). Mood induction with olfactory stimuli reveals differential affective responses in males and females. Chem. Senses 34, 77-84. doi: 10.1093/chemse/ bjn 054

Small, D. M., Jones-Gotman, M., and Dagher, A. (2003). Feeding-induced dopamine release in dorsal striatum correlates with meal pleasantness ratings in healthy human volunteers. Neuroimage 19, 1709 1715. doi: 10.1016/s1053-8119(03) 00253-2

Small, S. A., Schobel, S. A., Buxton, R. B., Witter, M. P., and Barnes, C. A. (2011). A pathophysiological framework of hippocampal dysfunction in ageing and disease. Nat. Rev. Neurosci. 12, 585-601. doi: 10. 1038/nrn3085

Sullivan, R. M., Landers, M., Yeaman, B., and Wilson, D. A. (2000).
Good memories of bad events in infancy. Nature 407, 38-39. doi: 10. $1038 / 35024156$

Sullivan, R. M., and Wilson, D. A. (1993). Role of the amygdala complex in early olfactory associative learning. Behav. Neurosci. 107, 254263. doi: 10.1037/0735-7044.107.2. 254

Tanabe, T., Yarita, H., Iino, M., Ooshima, Y., and Takagi, S. F. (1975). An olfactory projection area in orbitofrontal cortex of the monkey. J. Neurophysiol. 38, 1269-1283.

Tort, A. B., Komorowski, R., Kopell, N., and Eichenbaum, H. (2011). A mechanism for the formation of hippocampal neuronal firing patterns that represent what happens where. Learn. Mem. 18, 718-727. doi: 10.1101/lm.2307711

Turner, B. H., Gupta, K. C., and Mishkin, M. (1978). The locus and cytoarchitecture of the projection areas of the olfactory bulb in Macaca mulatta. J. Comp. Neurol. 177, 381396. doi: 10.1002/cne. 901770303

Turner, B. H., and Mishkin, M. (1978). A reassessment of the direct projections of the olfactory bulb. Brain Res. 151, 375-380. doi: 10. 1016/0006-8993(78)90892-2

Ulrich-Lai, Y. M., and Herman, J. P. (2009). Neural regulation of endocrine and autonomic stress responses. Nat. Rev. Neurosci. 10, 397-409. doi: 10.1038/ nrn2647

Varendi, H., and Porter, R. H. (2001). Breast odour as the only maternal stimulus elicits crawling towards the odour source. Acta Paediatr. 90, 372-375. doi: 10.1111/j.1651-2227. 2001.tb00434.x

Vermetten, E., Bremner, J. D., Skelton, L., and Spiegel, D. (2007). Ptsd and Vietnam Veterans. Science 315, 184187.

Weiskrantz, L. (1956). Behavioral changes associated with ablation of the amygdaloid complex in monkeys. J. Comp. Physiol. Psychol. 49, 381-391. doi: 10.1037/ h0088009
Wilson, D. A. (1998). Habituation of odor responses in the rat anterior piriform cortex. J. Neurophysiol. 79, 1425-1440.

Wilson, D. A. (2009). Olfaction as a model system for the neurobiology of mammalian short-term habituation. Neurobiol. Learn. Mem. 92, 199-205. doi: 10.1016/j.nlm.2008. 07.010

Wilson, D. A., and Linster, C. (2008). Neurobiology of a simple memory. J. Neurophysiol. 100, 2-7. doi: 10. 1152/jn.90479.2008

Wilson, D. A., and Stevenson, R. J. (2003a). The fundamental role of memory in olfactory perception. Trends Neurosci. 26, 243247. doi: 10.1016/s0166-2236(03) 00076-6

Wilson, D. A., and Stevenson, R. J. (2003b). Olfactory perceptual learning: the critical role of memory in odor discrimination. Neurosci. Biobehav. Rev. 27, 307-328. doi: 10 . 1016/s0149-7634(03)00050-2

Wilson, D. A., and Stevenson, R. J. (2006). Learning to Smell. Baltimore: The Johns Hopkins University Press. Wilson, D. A., and Sullivan, R. M. (2011). Cortical processing of odor objects. Neuron 72, 506-519. doi: 10. 1016/j.neuron.2011.10.027

Witter, M. P., and Amaral, D. G. (1991). Entorhinal cortex of the monkey: V. Projections to the dentate gyrus, hippocampus, and subicular complex. J. Comp. Neurol. 307, 437-459.

Wysocki, C. J., and Preti, G. (2004) Facts, fallacies, fears, and frustrations with human pheromones. Anat. Rec. A Discov. Mol. Cell. Evol. Biol. 281, 1201-1211. doi: 10. 1002/ar.a.20125

Yeomans, M. R. (2006). Olfactory influences on appetite and satiety in humans. Physiol. Behav. 89, 10-14. doi: 10.1016/j.physbeh.2006. 01.029

Yeshurun, Y., and Sobel, N. (2010). An odor is not worth a thousand words: from multidimensional odors to unidimensional odor objects. Annu. Rev. Psychol. 61, 219-241. doi: 10. 1146/annurev.psych.60.110707. 163639

Zald, D. H. (2003). The human amygdala and the emotional evaluation of sensory stimuli. Brain Res. Brain Res. Rev. 41, 88-123. doi: 10.1016/s01650173(02)00248-5

Zald, D. H., and Pardo, J. V. (1997). Emotion, olfaction, and the human amygdala: amygdala activation during aversive olfactory stimulation. Proc. Natl. Acad. Sci. U S A 94, 41194124. doi: 10.1073/pnas.94.8.4119

Zhang, J., and Webb, D. M. (2003). Evolutionary deterioration of the vomeronasal pheromone transduction pathway in catarrhine primates. Proc. Natl. Acad. Sci. U S A 100, 8337-8341. doi: 10.1073/pnas. 1331721100

Zucco, G. M., Aiello, L., Turuani, L., and Koster, E. (2012). Odor-evoked autobiographical memories: age and gender differences along the life span. Chem. Senses 37, 179-189. doi: 10.1093/chemse/bjr089

Conflict of Interest Statement: The authors declare that the research was conducted in the absence of any commercial or financial relationships that could be construed as a potential conflict of interest.

Received: 29 May 2013; accepted: 23 September 2013; published online: 10 October 2013.

Citation: Kadohisa M (2013) Effects of Odor on Emotion, with Implications. Front. Syst. Neurosci. 7:66. doi: 10.3389/fnsys.2013.00066

This article was submitted to the journal Frontiers in Systems Neuroscience. Copyright (c) 2013 Kadohisa. This is an open-access article distributed under the terms of the Creative Commons Attribution License (CC BY). The use, distribution or reproduction in other forums is permitted, provided the original author(s) or licensor are credited and that the original publication in this journal is cited, in accordance with accepted academic practice. No use, distribution or reproduction is permitted which does not comply with these terms. 